\title{
Oxidative cyclization of aldehyde thiosemicarbazones induced by potassium ferricyanide and by tris( $p$-bromophenyl)amino hexachloroantimoniate. A joint experimental and computational study
}

\author{
Paolo Lo Meo,* Michelangelo Gruttadauria, and Renato Noto* \\ Dipartimento di Chimica Organica "E. Paternò" - Università degli Studi di Palermo, Viale \\ delle Scienze, Parco d'Orleans, Pad. 17 - 90128 Palermo (Italy) \\ E-mail:rnoto@www.unipa.it
}

(received 19 Nov 04; accepted 19 Jan 05; published on the web 01 Feb 05)

\begin{abstract}
The oxidative ring closure reaction of some aryl-substituted thiosemicarbazones induced by "bona fide" one-electron abstracting agents was investigated, by means of both experimental and computational techniques. The corresponding 1,2,4-triazole derivatives were the only cyclization products observed. The occurrence of two slightly different mechanistic pathways for the reaction is discussed.
\end{abstract}

Keywords: Oxidative cyclization, thiosemicarbazones, 1,2,4-triazoles

\section{Introduction}

The cyclization of suitable open-chain organic molecules is a classical and very popular approach to the synthesis of heterocyclic derivatives, owing to both the large variety of heterocycles accessible through this way, and the large variety of conditions under which the reaction can be performed. ${ }^{1,2}$ Noticeably, when more than one product can be obtained at the same time in a particular reaction, good to excellent selectivities can often be achieved (and sometimes reverted) by means of a suitable choice of the cyclizing agent and conditions. ${ }^{2-5}$ Frequently, such cyclization reactions are induced by acidic media or electrophilic reagents. In the latter case, this might involve de facto a formal oxidation of the organic substrate, as an implicit consequence of the process (the cyclo-etherification or lactonization of unsaturated alcohols and acids induced by halogens or sulfinyl and selanyl halides provides a typical case). ${ }^{3,5-13}$ In other occasions, the cyclization mechanism involves a plain oxidation step electron abstraction or dehydrogenation - prior to the actual ring closure step. Examples of these reactions have been recently reviewed. ${ }^{14}$ 
Aldehyde semicarbazones and thiosemicarbazones $\mathbf{1}$ are typical substrates which may undergo ring closure processes induced by an oxidizing agent, to afford the corresponding 1,2,4triazole 2 and 1,3,4-oxa- or -thiadiazole 3 derivatives (Scheme 1). ${ }^{2 \mathrm{a}}$

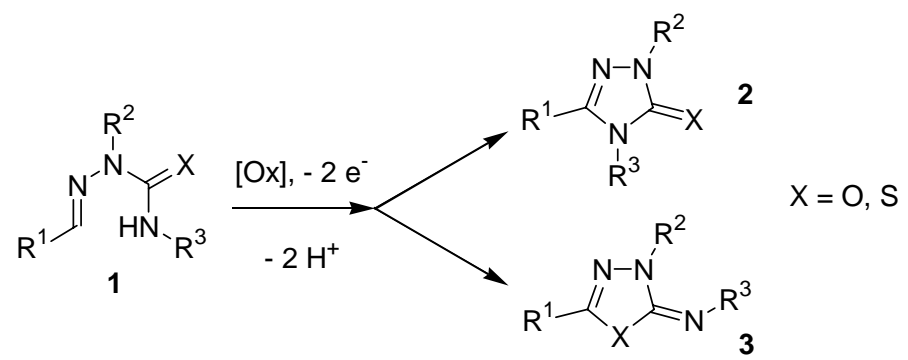

\section{Scheme 1}

Different reagents - such as bromine (or hypobromite), ${ }^{15,16}$ bromate or iodate, ${ }^{17}$ lead tetraacetate, ${ }^{18}$ and high-valent transition metal salts ${ }^{19-23}$ - have been used to perform these reactions. The former examples date up to the beginning of the last century; ${ }^{24}$ since the pioneer work by Gibson ${ }^{15}$ their synthetic and mechanistic aspects have been systematically studied. There is now enough evidence that the reaction may follow very different courses, depending on the substrate structure (in particular on the alkyl or aryl substituent groups placed on its main molecular framework) and on the oxidizing agent used. In particular, we have been interested in the oxidation of aryl-substituted thiosemicarbazones induced by high-valent $\left(\mathrm{Fe}^{3+}, \mathrm{Cu}^{2+}\right)$ metal salts. ${ }^{19-23}$ Despite the apparent similarity of these reagents, surprisingly we observed that very different results - both in terms of reaction regiochemistry and yields, and in terms of reaction kinetics - can be achieved by the use of different salts, depending on the hardness/softness of the metal cation (or, more properly, of the solvated metal-counteranion complex), as well as on its intrinsic oxidizing strength. On the grounds of a careful analysis of all available data, we proposed $^{2 \mathrm{a}, 22,23}$ (Scheme 2) that the formation of the 1,2,4-triazole ring could be induced by an attack of the oxidizing agent on the tail thioamide-like moiety of the molecule, followed by a single electron transfer (s.e.t.) step and then by a rate-limiting ring closure step. Differently, the formation of the 1,3,4-thiadiazole ring seemed induced by an attack of the metal cation as a Lewis acid on the imine nitrogen atom, followed by the ring closure step, and finally by the electron abstraction-dehydrogenation step.

Owing to the Lewis acid nature of the metal cations, some difficulties arise in the mechanistic study, because of the possible formation of different substrate-cation complexes, and of the inner-sphere nature of the electron abstraction process. Under these circumstances, it may be difficult to determine experimentally some details of the reaction pathway, as well as to identify the correct reaction intermediates. In particular, it seems still unclear whether the s.e.t. and the cyclization steps could be concerted processes, at least under certain circumstances (e.g. in the presence of $\mathrm{Fe}^{3+}$ salts). Therefore, we studied the reactivity of some suitable 2-methyl-4aryl- (1a-m) and 2,4-diaryl- (1n-y) benzaldehyde thiosemicarbazones (Scheme 3), towards 
suitable oxidizing agents having sharply different characteristics with respect to transition metal salts.

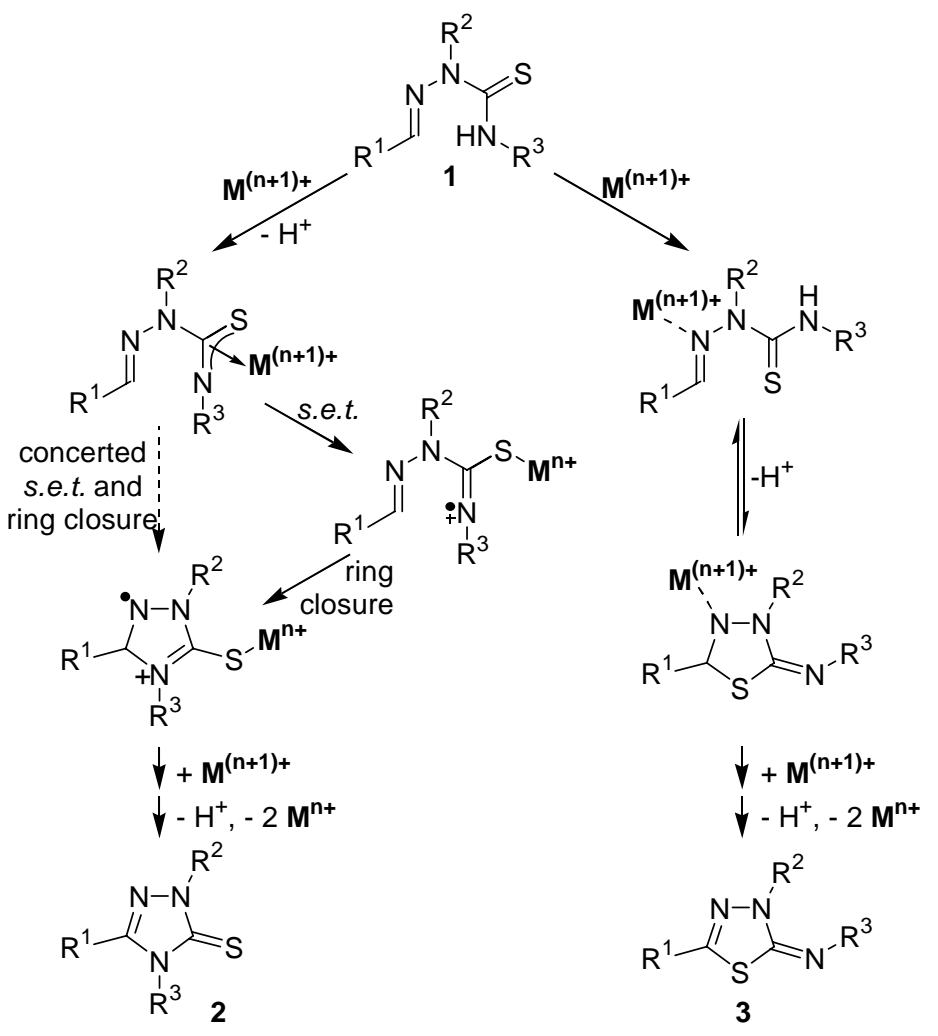

Scheme 2

\begin{tabular}{|c|c|c|c|c|c|c|c|}
\hline & $\mathrm{R}^{1}$ & $\mathbf{R}^{2}$ & $\mathbf{R}^{3}$ & & $\mathrm{R}^{1}$ & $\mathrm{R}^{2}$ & $\mathbf{R}^{3}$ \\
\hline a & $\mathrm{C}_{6} \mathrm{H}_{5}$ & $\mathrm{CH}_{3}$ & $\mathrm{C}_{6} \mathrm{H}_{5}$ & $\mathbf{n}$ & $\mathrm{C}_{6} \mathrm{H}_{5}$ & $\mathrm{C}_{6} \mathrm{H}_{5}$ & $\mathrm{C}_{6} \mathrm{H}_{5}$ \\
\hline b & $p-\mathrm{CH}_{3} \mathrm{OC}_{6} \mathrm{H}_{4}$ & $\mathrm{CH}_{3}$ & $\mathrm{C}_{6} \mathrm{H}_{5}$ & o & $p-\mathrm{CH}_{3} \mathrm{OC}_{6} \mathrm{H}_{4}$ & $\mathrm{C}_{6} \mathrm{H}_{5}$ & $\mathrm{C}_{6} \mathrm{H}_{5}$ \\
\hline c & $p-\mathrm{CH}_{3} \mathrm{C}_{6} \mathrm{H}_{4}$ & $\mathrm{CH}_{3}$ & $\mathrm{C}_{6} \mathrm{H}_{5}$ & $\mathbf{p}$ & $m-\mathrm{BrC}_{6} \mathrm{H}_{4}$ & $\mathrm{C}_{6} \mathrm{H}_{5}$ & $\mathrm{C}_{6} \mathrm{H}_{5}$ \\
\hline d & $p-\mathrm{BrC}_{6} \mathrm{H}_{4}$ & $\mathrm{CH}_{3}$ & $\mathrm{C}_{6} \mathrm{H}_{5}$ & $q$ & $p-\mathrm{CF}_{3} \mathrm{C}_{6} \mathrm{H}_{4}$ & $\mathrm{C}_{6} \mathrm{H}_{5}$ & $\mathrm{C}_{6} \mathrm{H}_{5}$ \\
\hline e & $m-\mathrm{ClC}_{6} \mathrm{H}_{4}$ & $\mathrm{CH}_{3}$ & $\mathrm{C}_{6} \mathrm{H}_{5}$ & $r$ & $p-\mathrm{NO}_{2} \mathrm{C}_{6} \mathrm{H}_{4}$ & $\mathrm{C}_{6} \mathrm{H}_{5}$ & $\mathrm{C}_{6} \mathrm{H}_{5}$ \\
\hline f & $p-\mathrm{CF}_{3} \mathrm{C}_{6} \mathrm{H}_{4}$ & $\mathrm{CH}_{3}$ & $\mathrm{C}_{6} \mathrm{H}_{5}$ & s: & $\mathrm{C}_{6} \mathrm{H}_{5}$ & $p-\mathrm{CH}_{3} \mathrm{OC}_{6} \mathrm{H}_{4}$ & $\mathrm{C}_{6} \mathrm{H}_{5}$ \\
\hline g & $p-\mathrm{NO}_{2} \mathrm{C}_{6} \mathrm{H}_{4}$ & $\mathrm{CH}_{3}$ & $\mathrm{C}_{6} \mathrm{H}_{5}$ & $\mathrm{t}$ & $\mathrm{C}_{6} \mathrm{H}_{5}$ & $p-\mathrm{CH}_{3} \mathrm{C}_{6} \mathrm{H}_{4}$ & $\mathrm{C}_{6} \mathrm{H}_{5}$ \\
\hline h & $\mathrm{C}_{6} \mathrm{H}_{5}$ & $\mathrm{CH}_{3}$ & $p-\mathrm{CH}_{3} \mathrm{OC}_{6} \mathrm{H}_{4}$ & $\mathbf{u}$ & $\mathrm{C}_{6} \mathrm{H}_{5}$ & $p-\mathrm{ClC}_{6} \mathrm{H}_{4}$ & $\mathrm{C}_{6} \mathrm{H}_{5}$ \\
\hline i & $\mathrm{C}_{6} \mathrm{H}_{5}$ & $\mathrm{CH}_{3}$ & $p-\mathrm{CH}_{3} \mathrm{C}_{6} \mathrm{H}_{4}$ & $\mathbf{v}$ & $\mathrm{C}_{6} \mathrm{H}_{5}$ & $\mathrm{C}_{6} \mathrm{H}_{5}$ & $p-\mathrm{CH}_{3} \mathrm{OC}_{6} \mathrm{H}_{4}$ \\
\hline j & $\mathrm{C}_{6} \mathrm{H}_{5}$ & $\mathrm{CH}_{3}$ & $m-\mathrm{CH}_{3} \mathrm{C}_{6} \mathrm{H}_{4}$ & w & $\mathrm{C}_{6} \mathrm{H}_{5}$ & $\mathrm{C}_{6} \mathrm{H}_{5}$ & $p-\mathrm{ClC}_{6} \mathrm{H}_{4}$ \\
\hline k & $\mathrm{C}_{6} \mathrm{H}_{5}$ & $\mathrm{CH}_{3}$ & $p-\mathrm{BrC}_{6} \mathrm{H}_{4}$ & $\mathbf{x}:$ & $\mathrm{C}_{6} \mathrm{H}_{5}$ & $\mathrm{C}_{6} \mathrm{H}_{5}$ & $m-\mathrm{ClC}_{6} \mathrm{H}_{4}$ \\
\hline I & $\mathrm{C}_{6} \mathrm{H}_{5}$ & $\mathrm{CH}_{3}$ & $m-\mathrm{ClC}_{6} \mathrm{H}_{4}$ & $y$ & $\mathrm{C}_{6} \mathrm{H}_{5}$ & $\mathrm{C}_{6} \mathrm{H}_{5}$ & $p-\mathrm{NO}_{2} \mathrm{C}_{6} \mathrm{H}_{4}$ \\
\hline m & $\mathrm{C}_{6} \mathrm{H}_{5}$ & $\mathrm{CH}_{3}$ & $p-\mathrm{NO}_{2} \mathrm{C}_{6} \mathrm{H}_{4}$ & $\mathbf{z}:$ & $\mathrm{C}_{6} \mathrm{H}_{5}$ & $\mathrm{H}$ & $\mathrm{C}_{6} \mathrm{H}_{5}$ \\
\hline
\end{tabular}

\section{Scheme 3}


Potassium ferricyanide (KFC) and tris( $p$-bromophenyl)amino hexachloroantimoniate (TPBA) were chosen, whose use in cyclization reactions has been seldom reported previously. ${ }^{25}$ They are both bona fide one-electron abstracting agents. In particular, the former one cannot act as a Lewis acid, thus it is able induce only "outer-sphere" electron transfer processes; therefore, it offers us the possibility to investigate the behavior of the "bare" organic substrate. Differently, TPBA contains a radical-cation species soluble in low polarity solvent media, which allows us to extend the study of this reaction beyond the usual polar solvents (water, alcohols, acetonitrile). Finally, in order to achieve a better understanding of the process, we supplied also a computational study of suitable model molecules.

\section{Results and Discussion}

\section{Analytical data}

As a first step, we investigated the quantitative aspects of the reaction performed on some suitable substrates (Tables 1 and 2). The reactions with KFC were performed in a boiling ethanol-water 4:1 mixture as solvent, as best compromise between the solubilities of the inorganic salt and organic substrates. The reactions with TPBA were performed in anhydrous dichloromethane under Ar atmosphere at $298 \mathrm{~K}$. With both oxidizing agents, the only cyclization products observed were the corresponding 1,2,4-triazoles in variable yields (together with unreacted substrate and eventually some unidentified hydrolysis or decomposition by-products, but no trace of the corresponding 1,3,4-thiadiazole derivatives).

Table 1. Reaction times and yields with KFC

\begin{tabular}{|c|c|c|c|c|}
\hline Substrate & $\begin{array}{l}\text { Reaction } \\
\text { Time }\end{array}$ & $\begin{array}{l}\% \\
2 \\
\end{array}$ & Recov. 1 & Notes \\
\hline 1a & $60 \mathrm{~min}$ & 65 & 25 & without $\mathrm{NaHCO}_{3}$ \\
\hline $1 \mathbf{a}$ & $15 \mathrm{~min}$ & 96 & - & with $\mathrm{NaHCO}_{3}$ \\
\hline $1 b$ & $10 \mathrm{~min}$ & 99 & - & with $\mathrm{NaHCO}_{3}$ \\
\hline $1 g$ & $480 \mathrm{~min}$ & - & 50 & with $\mathrm{NaHCO}_{3}$ \\
\hline 1n & $30 \mathrm{~min}$ & 85 & 12 & with $\mathrm{NaHCO}_{3}$ \\
\hline 10 & $30 \mathrm{~min}$ & 90 & - & with $\mathrm{NaHCO}_{3}$ \\
\hline 1r & $60 \mathrm{~min}$ & 50 & - & with $\mathrm{NaHCO}_{3}$ \\
\hline $1 v$ & $90 \mathrm{~min}$ & 60 & 40 & with $\mathrm{NaHCO}_{3}$ \\
\hline $1 y$ & $90 \mathrm{~min}$ & 75 & - & with $\mathrm{NaHCO}_{3}$ \\
\hline $1 z$ & $90 \mathrm{~min}$ & - & - & with $\mathrm{NaHCO}_{3}$ \\
\hline
\end{tabular}

Noticeably, we observed that with KFC the reaction yield is greatly improved by the addition of a slight excess of a base such as $\mathrm{NaHCO}_{3}$. As a matter of fact, because the oxidation process also involves the formation of two equivalents of $\mathrm{H}^{+}$, this may induce both the partial 
hydrolysis of the organic substrate and the decomposition of the ferrocyanide reduction byproduct, with formation of $\mathrm{HCN}$ and blocking of the residual oxidizing agent as Prussian blue, according to the following reactions:

$6 \mathrm{H}^{+}+\mathrm{Fe}(\mathrm{CN})_{6}^{4-} \rightarrow \mathrm{Fe}^{2+}+6 \mathrm{HCN}$

$\left.\mathrm{Fe}^{2+}+\mathrm{Fe}(\mathrm{CN})_{6}{ }^{3-} \rightarrow \mathrm{Fe}\left[\mathrm{Fe}(\mathrm{CN})_{6}\right)\right] \downarrow$

By the addition of $\mathrm{NaHCO}_{3}$ the occurrence of these secondary reactions is effectively avoided, and consequently appreciable amounts of Prussian blue are not detected.

Table 2. Reaction times and yields with TPBA

\begin{tabular}{llll}
\hline Substrate & $\begin{array}{l}\text { Reaction } \\
\text { Time }\end{array}$ & $\%$ & \\
& 2 min & 97 & Recov. 1 \\
\hline $\mathbf{1 a}$ & $60 \mathrm{~min}$ & - & 100 \\
$\mathbf{1 g}$ & $30 \mathrm{~min}$ & 80 & - \\
$\mathbf{1 n}$ & $120 \mathrm{~min}$ & 15 & - \\
$\mathbf{1 r}$ & $120 \mathrm{~min}$ & 65 & - \\
$\mathbf{1 y}$ & & & \\
\hline
\end{tabular}

We already knew that the reaction with $\mathrm{FeCl}_{3}$ of substrates $\mathbf{1 a}, \mathbf{1 b}$ and $\mathbf{1 r}$ provides both the corresponding 1,2,4-triazole and 1,3,4-thiadiazole derivatives, ${ }^{21}$ while the triazole is the only product for $\mathbf{1 n}, \mathbf{1 o}, \mathbf{1} \mathbf{v}$ and $\mathbf{1 y},{ }^{23}$ and the thiadiazole is the only product for $\mathbf{1 g}$ and $\mathbf{1 z} .^{19,21}$ Interestingly, data reported in Tables 1 and 2 show the occurrence of no cyclization product for the latter two substrates; in particular, $\mathbf{1 z}$ undergoes almost complete decomposition in the reaction conditions adopted. This confirms the crucial role as a Lewis acid of the oxidizing agent in order to achieve the formation of the thiadiazole derivatives. It should be remembered that protic acids or non-oxidizing Lewis acids effectively catalyze the formation of the corresponding thiadiazolidines from thiosemicarbazones. ${ }^{2 a, d-e, 26,27}$ Data in Table 1 also suggest that the replacement of a methyl group with a phenyl group on the $\mathrm{N}(2)$ nitrogen atom of the main molecular framework, makes the reaction slower and less effective. This behavior is similar to that observed for the oxidation of the same substrates with $\mathrm{Cu}\left(\mathrm{ClO}_{4}\right)_{2}$, but opposite with respect to that observed for the reaction with $\mathrm{FeCl}_{3}{ }^{23}$

\section{Competitive reactivities}

As a second step, we evaluated the relative reactivities of our substrates, by means of suitable competitive experiments (see experimental). Assumed 1a as the reference substrate for 1a-1, and 1n as the reference substrate for $\mathbf{1 n - y}$, data obtained are collected in Table 3. Noticeably, the relative reactivity between the two reference substrates is $k_{1 \mathbf{n}} / k_{1 \mathbf{a}}=0.20 \pm 0.01$ for the reaction with KFC and $k_{1 \mathbf{n}} / k_{1 \mathbf{a}}=1.16 \pm 0.05$ for the reaction with TPBA. Substrate $\mathbf{1 n}$ had been already found less reactive than $1 \mathbf{a}$ with $\mathrm{Cu}\left(\mathrm{ClO}_{4}\right)_{2}$, but more reactive towards $\mathrm{FeCl}_{3}$. Experimental data can be easily treated by means of Hammett's equation, providing the results summarized in Table 4. 
Table 3. Relative reactivates for substrates 1a-y (all data affected by a $\pm 4 \%$ indetermination)

\begin{tabular}{llllllll}
\hline Substrate & KFC & TPBA & $\begin{array}{l}\text { Reference } \\
\text { Substrate }\end{array}$ & Substrate & KFC & TPBA & $\begin{array}{l}\text { Reference } \\
\text { Substrate }\end{array}$ \\
\hline $\mathbf{1 a}$ & 1 & 1 & $\mathbf{1 a}$ & $\mathbf{1 n}$ & 1 & 1 & $\mathbf{1 n}$ \\
$\mathbf{1 b}$ & 3.93 & 1.87 & $\mathbf{1 a}$ & $\mathbf{1 0}$ & 3.82 & 3.70 & $\mathbf{1 n}$ \\
$\mathbf{1 c}$ & 1.59 & 1.51 & $\mathbf{1 a}$ & $\mathbf{1 p}$ & 0.219 & 0.193 & $\mathbf{1 n}$ \\
$\mathbf{1 d}$ & 0.375 & 0.601 & $\mathbf{1 a}$ & $\mathbf{1 q}$ & 0.0971 & 0.0910 & $\mathbf{1 n}$ \\
$\mathbf{1 e}$ & 0.272 & 0.416 & $\mathbf{1 a}$ & $\mathbf{1 r}$ & 0.0243 & 0.0258 & $\mathbf{1 n}$ \\
$\mathbf{1 f}$ & 0.185 & 0.280 & $\mathbf{1 a}$ & $\mathbf{1 s}$ & 0.659 & 1.08 & $\mathbf{1 n}$ \\
$\mathbf{1 h}$ & 0.505 & 1.79 & $\mathbf{1 a}$ & $\mathbf{1 t}$ & 0.767 & 0.912 & $\mathbf{1 n}$ \\
$\mathbf{1 i}$ & 0.698 & 1.45 & $\mathbf{1 a}$ & $\mathbf{1 u}$ & 1.53 & 0.914 & $\mathbf{1 n}$ \\
$\mathbf{1 j}$ & 0.851 & 1.11 & $\mathbf{1 a}$ & $\mathbf{1 v}$ & 0.794 & 2.55 & $\mathbf{1 n}$ \\
$\mathbf{1 k}$ & 2.40 & 0.785 & $\mathbf{1 a}$ & $\mathbf{1 w}$ & 1.16 & 0.492 & $\mathbf{1 n}$ \\
$\mathbf{1 l}$ & 3.21 & 0.566 & $\mathbf{1 a}$ & $\mathbf{1 x}$ & 1.33 & 0.292 & $\mathbf{1 n}$ \\
$\mathbf{1 m}$ & 4.37 & 0.272 & $\mathbf{1 a}$ & $\mathbf{1 y}$ & 2.35 & 0.0712 & $\mathbf{1 n}$ \\
\hline
\end{tabular}

Table 4. Hammett correlations

\begin{tabular}{llll}
\hline $\begin{array}{l}\text { Oxidizing } \\
\text { Agent }\end{array}$ & Substrates & $\log _{10}\left(k_{X} / k_{H}\right)=$ & Notes \\
\hline KFC & $\mathbf{1 a - f}$ & $(0.03 \pm 0.04)+(-1.63 \pm 0.13) \sigma_{X}$ & $\mathrm{n}=6, \mathrm{r}=0.987$ \\
& $\mathbf{1 a}, \mathbf{h}-\mathbf{l}$ & $(0.05 \pm 0.02)+(+1.25 \pm 0.10) \sigma_{X}$ & $\mathrm{n}=6, \mathrm{r}=0.989$ \\
& $\mathbf{1 n - r}$ & $(0.03 \pm 0.03)+(-2.00 \pm 0.06) \sigma_{X}$ & $\mathrm{n}=5, \mathrm{r}=0.999$ \\
& $\mathbf{1 n}, \mathbf{s}-\mathbf{u}$ & $(0.02 \pm 0.01)+(+0.57 \pm 0.04) \sigma_{X}$ & $\mathrm{n}=4, \mathrm{r}=0.996$ \\
& $\mathbf{1 n}, \mathbf{v}-\mathbf{y}$ & $(0.00 \pm 0.02)+(+0.44 \pm 0.04) \sigma_{X}$ & $\mathrm{n}=5, \mathrm{r}=0.985$ \\
TPBA & $\mathbf{1 a - f}$ & $(0.00 \pm 0.01)+(-1.05 \pm 0.03) \sigma_{X}$ & $\mathrm{n}=6, \mathrm{r}=0.998$ \\
& $\mathbf{1 a}, \mathbf{h}-\mathbf{l}$ & $(0.03 \pm 0.01)+(-0.74 \pm 0.03) \sigma_{X}$ & $\mathrm{n}=6, \mathrm{r}=0.996$ \\
& $\mathbf{1 n}-\mathbf{r}$ & $(0.01 \pm 0.01)+(-2.02 \pm 0.03) \sigma_{X}$ & $\mathrm{n}=5, \mathrm{r}=0.999$ \\
& $\mathbf{1 n}, \mathbf{s}-\mathbf{u}$ & $(0.00 \pm 0.01)+(-0.16 \pm 0.04) \sigma_{X}$ & $\mathrm{n}=4, \mathrm{r}=0.947$ \\
& $\mathbf{1 n}, \mathbf{v}-\mathbf{y}$ & $(0.00 \pm 0.01)+(-1.47 \pm 0.01) \sigma_{X}$ & $\mathrm{n}=5, \mathrm{r}=0.985$ \\
\hline
\end{tabular}

Noticeably, the datum for $\mathbf{1 m}$ with KFC goes beyond the correlation line for its homologous substrates 1a,h-l. Suitable competitive experiments on the 2-methyl-4-phenyl-thiosemicarbazone of 1-deutero-benzaldehyde (i.e. the deuterated analogous of 1a, see experimental) evidenced a small secondary isotope effect: $k_{\mathbf{1 a ( D )}} / k_{\mathbf{1 a ( H )}}=1.06 \pm 0.03$ with $\mathbf{K F C} ; k_{\mathbf{1 a}(\mathbf{D})} / k_{\mathbf{1 a}(\mathbf{H})}=1.12 \pm 0.05$ with TPBA. A similar effect had been already observed for the reaction of the same substrates with $\mathrm{Cu}\left(\mathrm{ClO}_{4}\right)_{2}$. These results, in particular the different values of the susceptivity constants $\boldsymbol{\rho}$, should be in turn compared with the corresponding data already reported for the oxidation of the same substrates with $\mathrm{FeCl}_{3}$ and $\mathrm{Cu}\left(\mathrm{ClO}_{4}\right)_{2},{ }^{21-23}$ summarized in Table 5. Analysis of the present results seems to confirm the mechanistic hypotheses previously summarized in Scheme 2. 
Table 5. Hammett $\boldsymbol{\rho}$ values for different oxidizing agents

\begin{tabular}{|c|c|c|c|c|c|c|}
\hline $\begin{array}{l}\text { Oxidizing } \\
\text { Agent }\end{array}$ & $\begin{array}{l}\text { Substrates } \\
\text { la-f }\end{array}$ & 1a,h-1 & $1 n-r$ & $1 \mathrm{n}, \mathrm{s}-\mathrm{u}$ & $1 \mathrm{n}, \mathrm{v}-\mathrm{y}$ & $\frac{k_{1 n}}{k_{1 a}}$ \\
\hline $\mathrm{FeCl}_{3}$ & -2.07 & -0.96 & -3.02 & -0.37 & (0) & $1.60 \pm 0.08$ \\
\hline $\mathrm{Cu}\left(\mathrm{ClO}_{4}\right)_{2}$ & -2.20 & $*$ & -2.07 & +0.70 & $*$ & $0.25 \pm 0.01$ \\
\hline KFC & -1.63 & +1.25 & -2.00 & +0.57 & +0.44 & $0.20 \pm 0.01$ \\
\hline TPBA & -1.05 & -0.74 & -2.02 & -0.16 & -1.47 & $1.16 \pm 0.05$ \\
\hline
\end{tabular}

*: values of $\log _{10}\left(k_{X} / k_{H}\right) v s . \sigma$ substituent constants give a non-linear bell-shaped plot.

Data for KFC (considered the outer-sphere nature of the electron abstraction process induced by the ferricyanide ion) indeed suggest the occurrence of a rapid s.e.t. step. Thus, the subsequent ring closure process is the actual rate limiting step, as accounted for by the secondary isotope effect. Data also confirm that the moiety of the substrate actually involved in the electron abstraction process is the thioamide-like one. As a matter of fact, the role as an internal electrophile played by the $\mathrm{N}(4)$ nitrogen atom during the ring closure step is unambiguously accounted for by the corresponding positive $\rho$ values for the substitution on the N(4)-phenyl ring. It is interesting to notice that $\mathbf{1 m}$ is found to be less reactive than expected on the basis of the Hammett's correlation for substrates 1a,h-l. This can be easily justified considering that only a strong electron-withdrawing substituent (such as $p-\mathrm{NO}_{2}$ ) on the $\mathrm{N}(4)$-phenyl ring could be able to significantly decrease the rate of the electron transfer step. The role as an internal electrophile played by N(4) is also indirectly confirmed by the replacement on the N(2) nitrogen atom of a methyl group with a phenyl group, which makes the reaction up to 12 times slower. The presence of a $\pi$-conjugating group on $\mathrm{N}(2)$ results in a "dilution" of the electrophilic character for N(4), so it exerts a leveling action on substituent effects for the N(4)-phenyl ring. As a consequence (and according to the well known "reactivity-selectivity principle"), the corresponding $\boldsymbol{\rho}$ values for the $\mathrm{N}$ (4)-phenyl ring substitution decrease from +1.25 (for 1a,h-l) to +0.44 (for $\mathbf{1 n}, \mathbf{v}-\mathbf{y}$ ). The latter value should be compared to the corresponding one for the substitution on the $\mathrm{N}(2)$-phenyl ring $(\boldsymbol{\rho}=+0.57$ for $\mathbf{1 n}, \mathbf{s}-\mathbf{u})$, indicating that the substitution on either phenyl ring has comparable effects. According to the reactivity-selectivity principle, the replacement of a methyl group with a phenyl group on $\mathrm{N}(2)$ also causes a small increase of substituent effects on the phenyl group linked to the iminic $-\mathrm{CH}=\mathrm{N}$ - moiety. The corresponding $\boldsymbol{\rho}$ value passes from -1.63 for $1 \mathrm{a}-\mathrm{f}$ to 2.00 for 1n-r (it should be reminded that these negative values account for a nucleophilic behavior of the iminic $\mathrm{C}$ atom).

Experimental data do not allow us to identify the correct nature and structure of the actual deelectronized open-chain and ring-closed intermediates for the overall process. The present case, in fact, cannot be compared with other known situations, such as the formation of nitrenium cations from $\mathrm{N}$-chloroanilines ${ }^{28,29}$ (for which correlation of kinetic data with $\sigma^{+}$constants is expected, with $\boldsymbol{\rho}$ values around -6). Nonetheless, on the basis of the reports by O'Mahony et al. on the oxidation of arylhydrazones, ${ }^{30}$ we can definitively rule out the occurrence of an attack of 
the oxidizing species on the $\mathrm{N}(2)$ atom. As a matter of fact, in the latter case a $\boldsymbol{\rho}$ value for substrates 1n,s-u about three times higher than for substrates 1n-r should be expected.

The reaction with TPBA shows remarkable differences, which suggest that the mechanistic picture should be partly modified. As a matter of fact, the increased reactivity of $\mathrm{N}(2)$-phenyl substrates with respect to the corresponding $\mathrm{N}(2)$-methyl substrates, and the concomitant increase of substituent effect on the iminic phenyl group (in striking contradiction with the reactivity-selectivity principle), cannot be explained in terms of a ring-closure step subsequent to a plain electron abstraction step. However, these findings are consistent with the hypothesis that electron abstraction and ring closure would be concerted processes. We can imagine, indeed, that the replacement of a methyl group with a phenyl group causes at the same time both an increase in the process rate (making the electron abstraction easier) and a significant forward shift of the transition state. It should be noticed that TPBA shows a much larger variation of the $\rho$ value than KFC for the substitution on the iminic phenyl group ( $\boldsymbol{\rho}$ values pass from -1.05 for 1a-f to -2.02 for 1n-r). A similar large variation was found also for the reactions with $\mathrm{FeCl}_{3}$; however, the latter oxidizing agent shows a strong decrease of the substituent effects on the N(4) phenyl ring on passing from $\mathrm{N}(2)$-methyl to $\mathrm{N}(2)$-phenyl substrates, in agreement with the reactivityselectivity principle. Differently, an increase in substituent effects is shown for TPBA. The latter anomaly could be easily explained, in our opinion, on the grounds of the unfavorable steric effect of the $\mathrm{N}(2)$-phenyl group on the approach of the bulky organic radical-cation towards the substrate.

\section{Computational study}

In order to investigate the correct structure of the species involved in the process, and in general to achieve deeper information and a more detailed picture of the reaction course, we performed a computational study on the behavior of a suitable model system, namely the 2,4-dimethylthiosemicarbazone of acetaldehyde 4 and its isothio-semicarbazone tautomeric form 5 (Scheme 4). It should be preliminarily noticed that the possible equilibrium between these two tautomeric forms must be taken into account, because in general the interaction of thiosemicarbazones with transition metal cations actually involves their thiole-like tautomeric form. ${ }^{31}$ Furthermore, assumed the electron transfer and the cyclization as distinct mechanistic steps, both these tautomers may undergo an electron abstraction process, to afford the corresponding radical cations $4^{+\cdot}$ and $5^{+}$; these cations may subsequently lose $\mathrm{H}^{+}$to give the same radical species 6 . Finally, $4^{+}, 5^{+\cdot}$ and 6 may all in principle undergo the ring closure process, via the intermediate species 7, 8 and $\mathbf{9}$ respectively, to afford the final triazole $\mathbf{1 0 .}$ 


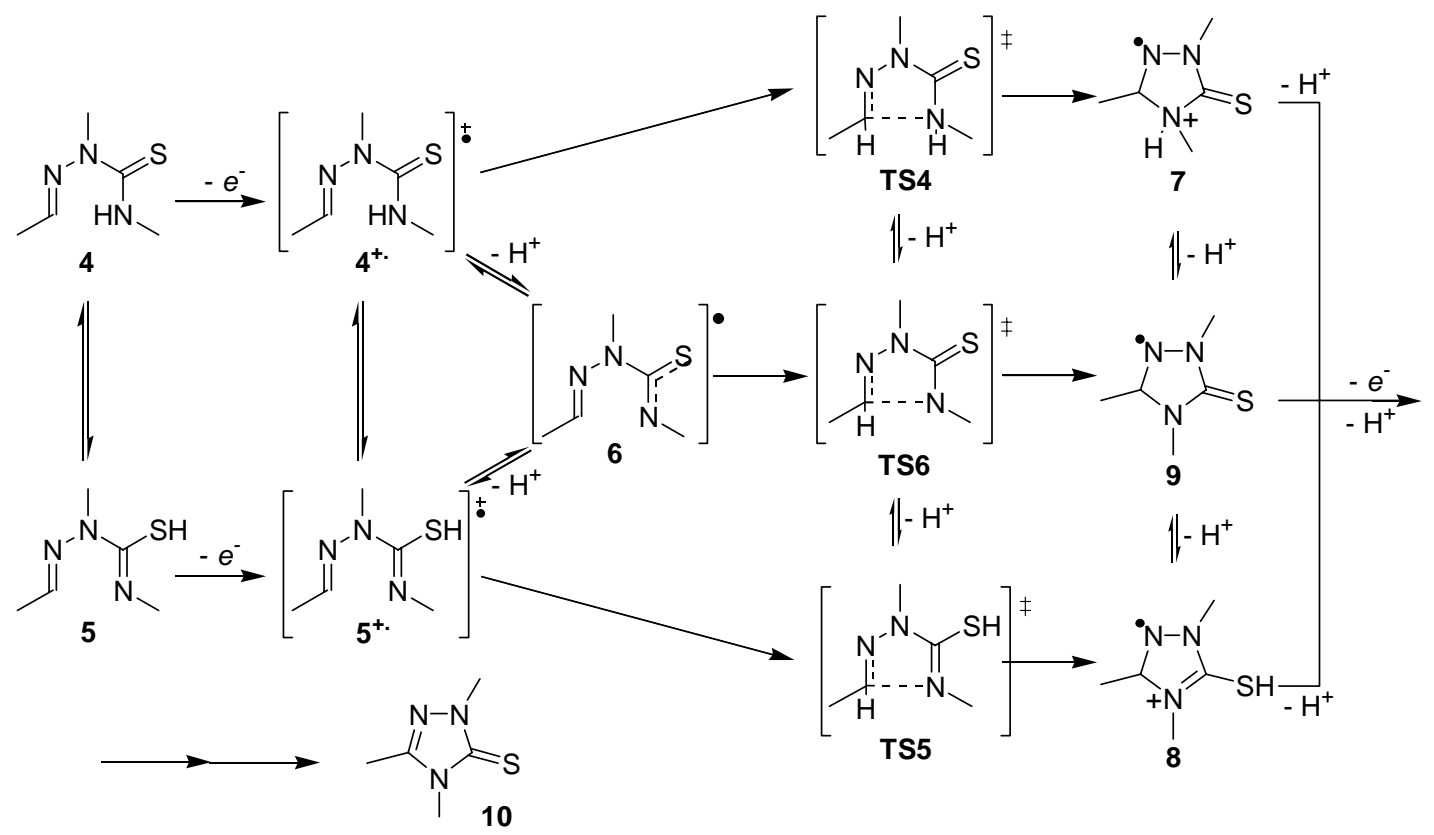

\section{Scheme 4}

As a first work, an exhaustive conformational analysis for species $4,5,4^{+}, 5^{+}$and 6 was needed. As a matter of fact, assumed an $E$ geometry for the iminic $-\mathrm{CH}=\mathrm{N}$ - double bond, the main framework of $\mathbf{4}$ might experience free internal rotation around three formal single bonds, namely $\mathrm{R}_{1} \mathrm{CHN}-\mathrm{NR}_{2-}$, $-\mathrm{NR}_{2}-\mathrm{CS}-$, and $-\mathrm{CS}-\mathrm{NHR}_{3}$. However, because of the possibility of electron conjugation, we may presume that the dihedral angle related to these bonds may actually have only two potential energy minima, namely at $0^{\circ}$ and $180^{\circ}$. As a consequence, eight main conformers for 4 can be drawn (Scheme 5), identified respectively as $000,00 \pi, 0 \pi 0,0 \pi \pi, \pi 00, \pi 0 \pi$, $\pi \pi 0$ and $\pi \pi \pi$, as a function of the aforesaid dihedral angles values. Similar analyses can be performed also on systems $4^{+}, 5,5^{+}$and 6 . These conformational searches were performed, in the gas phase, at the HF/3-21G* level of theory (results are collected in Table 6).
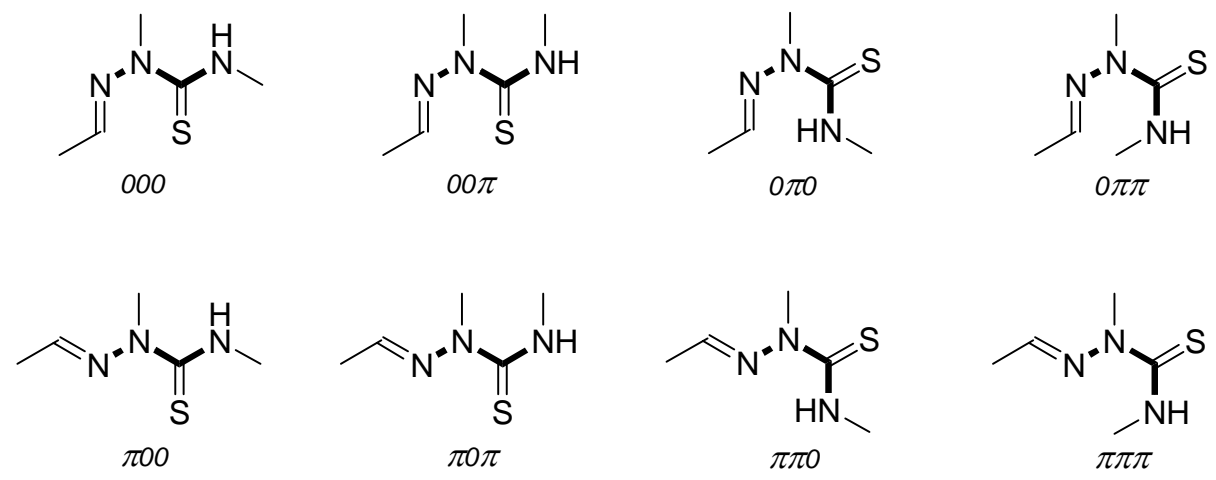

\section{Scheme 5}


Table 6. Energies of formation (hartrees) of models $4,4^{+}, 5,5^{+}$and 6 (gas phase, HF/3-21G*)

\begin{tabular}{|c|c|c|c|c|c|}
\hline Conformation & 4 & $4^{+}$. & 5 & $5^{+.}$ & 6 \\
\hline 000 & -752.70535 & $\begin{array}{l}\text { collapses to } \\
\pi 00\end{array}$ & -752.66291 & $\begin{array}{l}\text { collapses to } \\
\pi 00\end{array}$ & -752.07582 \\
\hline $00 \pi$ & -752.69881 & $\begin{array}{l}\text { collapses to } \\
\pi 0 \pi\end{array}$ & -752.66479 & $\begin{array}{l}\text { collapses to } \\
\pi 00\end{array}$ & -752.07114 \\
\hline $0 \pi 0$ & $\begin{array}{l}\text { collapses to } \\
\pi \pi 0\end{array}$ & $\begin{array}{l}\text { collapses to } \\
\pi \pi 0\end{array}$ & -752.66396 & -752.43702 & -752.07621 \\
\hline $0 \pi \pi$ & -752.70248 & $\begin{array}{l}\text { collapses to } \\
\pi \pi \pi\end{array}$ & collapses to $O 0 \pi$ & $\begin{array}{l}\text { collapses to } \\
\pi \pi \pi\end{array}$ & -752.07121 \\
\hline$\Pi 00$ & -752.69968 & -752.49000 & -752.67656 & -752.44688 & -752.08027 \\
\hline$\Pi 0 \pi$ & -752.69520 & -752.48186 & collapses to $\pi \pi \pi$ & -752.44133 & -752.06595 \\
\hline$\pi \pi 0$ & -752.72560 & -752.49125 & -752.65895 & -752.43716 & -752.08027 \\
\hline$\pi \pi \pi$ & -752.71021 & -752.47779 & -752.66515 & -752.43810 & -752.07353 \\
\hline
\end{tabular}

Data show that the $\pi \pi 0$ conformation is most stable form for $\mathbf{4}$ and $\mathbf{4}^{+}$, probably because of the favorable hydrogen bond interaction between the N(1) iminic nitrogen atom and the N(4)-H thioamide-like group. Presumably for a similar reason, the $\pi 00$ form is the most stable conformation for $\mathbf{5}$ and $\mathbf{5}^{+}$. For $\mathbf{6}$ the most stable conformer is a distorted $\pi \pi 0$ form in which the $\mathrm{CS}-\mathrm{NHR}_{3}$ dihedral angle is near to $90^{\circ}$. Both $\mathbf{4}$ and $\mathbf{4}^{+}$are predicted much more stable than their tautomeric forms $\mathbf{5}$ and $\mathbf{5}^{+}$in the gas phase (by about 30.8 and $27.8 \mathrm{kcal} / \mathrm{mole}$ respectively). Similarly, the transfer of $\mathrm{H}^{+}$from $4^{+}$to a water molecule is predicted to be a highly disfavored process (for $66.4 \mathrm{kcal} / \mathrm{mole}$ ). Nonetheless, such results could have been artifacts specifically due to the lack of a solvent environment. Considering that the "real" reaction is usually performed in a polar medium, the presence of an implicit solvent environment as a continuum can be easily accounted for by means of the COSMO method. ${ }^{32}$ Subjecting the optimized $\pi \pi 0$ conformations of $4, \mathbf{4}^{+}$and $\mathbf{6}$, as well as the optimized $\pi 00$ conformations of $\mathbf{5}$ and $\mathbf{5}^{+}$to a single point calculation with the COSMO procedure (water was assumed as solvent), data still confirm $\mathbf{4}$ and $\mathbf{4}^{+}$as more stable than 5 and $5^{+}$(by 34.6 and $23.0 \mathrm{kcal} / \mathrm{mole}$ respectively). However, the transfer of $\mathrm{H}^{+}$from $4^{+}$to $\mathrm{H}_{2} \mathrm{O}$ is predicted to be disfavored by only $2.9 \mathrm{kcal} / \mathrm{mole}$. The latter datum appears ambiguous, because the energy of formation of $\mathrm{H}_{3} \mathrm{O}^{+}$used in the calculation is presumably underestimated..$^{33}$ Furthermore, it should also be noticed that in the "real" reaction system different anions and bases may be present; therefore, everything considered, the loss of $\mathrm{H}^{+}$from $4^{+}$.is likely to be a favored process during the reaction course in solution.

At this point we had to establish whether the cyclization product could be actually formed from either $\mathbf{4}^{+}, \mathbf{5}^{+}$or $\mathbf{6}$. Thus, the three corresponding transition states - TS4, TS5 and TS6 respectively - were also optimized in the gas phase at the HF/3-21G* level of theory, and the optimized structures were also subjected to a single-point calculation with the COSMO procedure (Table 7). 
Table 7. Energies of formation (hartrees) of different models at various levels of theory

\begin{tabular}{lll}
\hline Model & HF/3-21G* (gas) & HF/3-21G*/COSMO \\
\hline $\mathbf{4} \pi \pi 0$ & -752.72560 & -752.73810 \\
$\mathbf{4}^{+\cdot} \pi \pi 0$ & -752.49125 & -752.55754 \\
$\mathbf{T S 4}$ & -752.43168 & -752.51123 \\
$\mathbf{5} \pi 00$ & -752.67656 & -752.68301 \\
$\mathbf{5}^{+\cdot} \pi 00$ & -752.44688 & -752.52092 \\
$\mathbf{T S 5}$ & -752.42636 & -752.49998 \\
$\mathbf{6} \pi \pi 0$ & -752.08009 & -752.09257 \\
$\mathbf{T S 6}$ & -752.06221 & -752.07523 \\
$\mathbf{7}$ & -752.48504 & -752.58101 \\
$\mathbf{8}$ & -752.49687 & -752.57963 \\
$\mathbf{9}$ & -752.14511 & -752.15913 \\
$\mathrm{H}_{2} \mathrm{O}$ & -75.58596 & -75.59689 \\
$\mathrm{H}_{3} \mathrm{O}^{+}$ & -75.89123 & -76.05723 \\
\hline
\end{tabular}

In the gas phase TS4 is predicted to be more stable than TS5 by $3.3 \mathrm{kcal} / \mathrm{mole}$. TS6 is not directly comparable to TS4 or TS5; however the ideal loss of $\mathrm{H}^{+}$from TS4 to afford TS6 is predicted to be disfavored by $40.3 \mathrm{kcal} / \mathrm{mole}$. In the presence of a continuous solvent medium TS4 is still more stable than TS5, but the loss of $\mathrm{H}^{+}$to afford TS6 now neatly becomes a favored process (by $15.3 \mathrm{kcal} / \mathrm{mole}$ ). Thus we may conclude that the cyclization step is likely to proceed via TS6. The predicted activation energy seems quite low $(11.2 \mathrm{kcal} / \mathrm{mole}$ in the gas phase, $10.9 \mathrm{kcal} /$ mole in solution). However it should be considered that no entropic term was taken into account; moreover, on the basis of the plausible electronic effect exerted by phenyl groups with respect to methyl groups, it may be easily predicted that 4 should be much more reactive than 1a or 1n. Further insights may be found on inspection of the Mulliken population analyses for the species examined (Table 8). As a matter of fact, calculated charge variations on the reaction centers on passing from 6 to TS6 are in agreement with the experimental Hammett's $\boldsymbol{\rho}$ values found. Differently, an incorrect charge variation on the thioamide-like - $\mathrm{N}(4) \mathrm{H}$ - group is calculated for the passage from $4^{+}$to TS4. Charge variations calculated for the passage $5^{+}$to TS5 are also correct; however, calculations unambiguously indicate that a reaction pathway via TS5 should be energetically disfavored. As a final remark, few words may be spent about the Nciclyzed intermediates 7, 8 and 9. Calculations, indeed, predict that the loss of $\mathrm{H}^{+}$from $\mathbf{7}$ or 8 to afford 9 should be a disfavored process in the gas phase, but a strongly favored process in solution.

Computational results, of course, may be immediately applied only to the reaction of our substrates with KFC. Nonetheless, they also provide useful hints in understanding the course of the reaction with other oxidizing agents. As a matter of fact, population analyses seem anyway to rule out the occurrence of any interaction between the $\mathrm{N}(4)$ atom and any electrophilic species, 
such as $\mathrm{H}^{+}$. Therefore, the interaction between $\mathrm{N}(4)$ and any oxidizing cation during the ring closure process appears to be unlikely. As a consequence, the occurrence of a transition state similar to TS5 seems reasonable for the reactions with TPBA, as well as with $\mathrm{Fe}^{3+}$ or $\mathrm{Cu}^{2+}$ salts. $^{34}$

Table 8. Mulliken charges for models $4^{+}, 5^{+}, 6$, TS4, TS5 and TS6

\begin{tabular}{|c|c|c|c|c|c|c|c|}
\hline $\begin{array}{l}\text { Theory } \\
\text { Level }\end{array}$ & Model & $\begin{array}{l}\text { Sum of } \\
\text { Charges on } \\
\text { the }-\mathrm{CH}=\mathrm{N}- \\
\text { Group }\end{array}$ & Diff. & $\begin{array}{l}\text { Charge on } \\
\mathrm{N}(4) \text { or the - } \\
\mathrm{N}(4) \mathrm{H}- \\
\text { Group }\end{array}$ & Diff. & $\begin{array}{l}\text { Charge } \\
\text { on } \\
\mathrm{N}(2)\end{array}$ & Diff. \\
\hline \multirow[t]{6}{*}{$\begin{array}{l}\mathrm{HF} / 3-21 \mathrm{G}^{*} \\
\text { (gas) }\end{array}$} & $4^{+}$ & +0.068 & \multirow[t]{2}{*}{+0.260} & -0.446 & \multirow[t]{2}{*}{+0.005} & -0.720 & \multirow[t]{2}{*}{+0.177} \\
\hline & TS4 & +0.328 & & -0.441 & & -0.543 & \\
\hline & $5^{+}$ & +0.118 & \multirow{2}{*}{+0.232} & -0.525 & \multirow{2}{*}{-0.146} & -0.507 & \multirow{2}{*}{-0.067} \\
\hline & TS5 & +0.350 & & -0.671 & & -0.574 & \\
\hline & 6 & +0.040 & \multirow{2}{*}{+0.072} & -0.426 & \multirow{2}{*}{-0.101} & -0.693 & \multirow{2}{*}{-0.002} \\
\hline & TS6 & +0.112 & & -0.527 & & -0.695 & \\
\hline \multirow{6}{*}{$\begin{array}{l}\mathrm{HF} / 3-21 \mathrm{G}^{*} / \\
\text { COSMO }\end{array}$} & $4^{+}$ & +0.086 & \multirow{2}{*}{+0.266} & -0.402 & \multirow{2}{*}{+0.007} & -0.694 & \multirow{2}{*}{+0.154} \\
\hline & TS4 & +0.352 & & -0.395 & & -0.540 & \\
\hline & $5^{+}$ & +0.152 & \multirow{2}{*}{+0.188} & -0.535 & \multirow{2}{*}{-0.120} & -0.481 & \multirow{2}{*}{-0.071} \\
\hline & TS5 & +0.340 & & -0.655 & & -0.552 & \\
\hline & 6 & +0.051 & \multirow{2}{*}{+0.075} & -0.469 & \multirow{2}{*}{-0.078} & -0.682 & \multirow{2}{*}{-0.002} \\
\hline & TS6 & +0.126 & & -0.547 & & -0.684 & \\
\hline
\end{tabular}

In conclusion, our study provides a detailed picture of the reaction mechanism for the oxidative cyclization of aldehyde thiosemicarbazones. In particular, the occurrence of slightly different mechanistic pathways for the formation of the 1.2.4-triazole ring (i. e. concerted or not concerted electron abstraction and ring closure steps) have been supported with a suitable analysis of experimental data. Useful insights on the reaction pathway, and in particular on the possible transition state for the ring closure step, have been provided also with the aid of computational results.

\section{Experimental Section}

Materials. All needed reagents were used as purchased, without further purification. Substrates 1a-z were prepared according to literature reports. ${ }^{21,23,35}$ Dichloromethane was purified by refluxing with $\mathrm{CaH}_{2}$ for three hours and distilling. 


\section{Quantitative oxidation experiments}

i) Reaction with KFC. The substrate $(0.3 \mathrm{mmoles})$ was dissolved in boiling ethanol $(8 \mathrm{~mL})$, then an aliquot $(2 \mathrm{~mL})$ of a stock KFC $0.32 \mathrm{M}$ and $\mathrm{NaHCO}_{3} 0.4 \mathrm{M}$ solution was added. The mixture was kept under reflux for a suitable time, then cooled and concentrated under reduced pressure; the residue was suspended in ethyl acetate and extracted twice with water and finally with brine. The organic layer was dried on sodium sulfate and concentrated under reduced pressure, and the final residue was chromatographated on silica gel with suitable light petrol-ethyl acetate mixtures as eluents.

ii) Reaction with TPBA. The substrate $(0.3$ mmoles $)$ was dissolved in anhydrous dichloromethane $(40 \mathrm{~mL})$ under Ar atmosphere at room temperature, then TPBA (0.62 mmoles) dissolved in anhydrous dichloromethane $(200 \mathrm{~mL})$ was added. The mixture was stirred for a suitable time at $298 \mathrm{~K}$, then concentrated under reduced pressure, and the final residue was chromatographated on silica gel with suitable light petrol-ethyl acetate mixtures as eluents.

Relative reactivity competitive experiments. The competitive method involves the reaction of a mixture of two different substrates $\boldsymbol{S}_{\boldsymbol{A}}$ and $\boldsymbol{S}_{\boldsymbol{B}}$ with a defective amount of the oxidizing agent. If the substrates react with the same mechanism, from the final concentrations of the two different products formed $\left(\boldsymbol{P}_{\boldsymbol{A}}\right.$ and $\boldsymbol{P}_{\boldsymbol{B}}$ respectively) and of the unreacted substrates, the relative reactivity can be calculated according to the equation:

$$
\frac{k_{B}}{k_{A}}=\frac{\ln \left(1+\frac{\left|P_{B}\right|}{\left|S_{B}\right|}\right)}{\ln \left(1+\frac{\left|P_{A}\right|}{\left|S_{A}\right|}\right)}
$$

i) Reaction with KFC. To a mixture of two different substrates (10 $\mu$ moles each) dissolved in boiling ethanol $(8 \mathrm{~mL})$ a stock aqueous solution of KFC $5 \mathrm{mM}(2 \mathrm{~mL})$ was added; the mixture was then kept under reflux for a suitable time (15 to $45 \mathrm{~min}$ ) and cooled. A small aliquot ( $c a$. $0.5 \mathrm{~mL})$ was transferred in a SEP-PAK ${ }^{\circledR} \mathrm{C} 18$ mini-column and eluted with water $(5 \mathrm{~mL})$ to eliminate the inorganic salts, then with acetonitrile $(2 \mathrm{~mL})$ to recover the organic substances; the latter eluate is analyzed by means of an HPLC apparatus.

ii) Reaction with TPBA. To a mixture of two different substrates (10 $\mu$ moles each) dissolved in anhydrous dichlorometane $(8 \mathrm{~mL})$, kept under $\mathrm{Ar}$ atmosphere at $298 \mathrm{~K}$, a freshly prepared solution of TPBA $5 \mathrm{mM}(2 \mathrm{~mL})$ was introduced; the mixture was then stirred for a suitable time (5 min). A small aliquot (ca. $0.5 \mathrm{~mL}$ ) was transferred in a SEP-PAK ${ }^{\circledR} \mathrm{C} 18$ mini-column and eluted with water $(5 \mathrm{~mL})$, then with acetonitrile $(2 \mathrm{~mL})$ to recover the organic substances; the latter eluate is analyzed by means of an HPLC apparatus. 
In order to evaluate the secondary isotope effect for the deuteriated compound 1a(D), its relative reactivities towards substrates $\mathbf{1 d}$ and $\mathbf{1 k}$ were measured, and the results were compared with the already known relative reactivities of $\mathbf{1 d}$ and $\mathbf{1 k}$ towards $\mathbf{1} \mathbf{a}(\mathbf{H})$.

Computational - $A b$ initio calculations were performed by means of the GAUSSIAN98 TM software package by Gaussian Inc. ${ }^{36}$ Data reported in Tables 6 and 7 have no ZPE correction. For the optimized structures of TS4, TS5 and TS6 the existence of only one imaginary frequency was confirmed by inspection of the Hessian matrix.

\section{Acknowledgements}

University of Palermo is gratefully acknowledged for financial support.

\section{Supplementary Information}

Cartesian matrices for the optimized structures of model species $4, \mathbf{4}^{+}, \mathbf{5}, \mathbf{5}^{+}, \mathbf{6}, \mathbf{6}, \mathbf{T S} 4$, TS5, TS6, 7, 8, 9 are provided.

\section{References and Notes}

1. Countless examples on this topic may be found in any heterocyclic chemistry textbook. See for example: Katritzky, A. R.; Lagowski, J. M. Principles of Heterocyclic Chemistry; Academic Press: New York, 1968. For other reviews see: Bird, C. W.; Cheeseman, G. W. H. "Intermolecular and intramolecular Cyclization reactions in ring synthesis" In Aromatic and Heteroaromatic Chemistry; Bird, C. W.; Cheeseman, G. W. H., Eds; Royal Society of Chemistry: London, 1977; Vol. 5, pp 65-112. See also: Taylor, E. C.; Turchi, I. J. Chem. Rev. 1977, 77, 181.

2. For a review on semi- and thiosemicarbazones see: (a) Lo Meo, P; Aprile, C.; D’Anna, F; Gruttadauria, M.; Riela, S.; Noto, R. Res. Adv. In Organic Chem. 2000, 1, 107 and references therein. See also: (b) Landquist, J. K. J. Chem. Soc. 1970, 63. (c) Martins Alho, M.; D’Accorso, N. B. J. Heterocycl. Chem. 2000, 37, 811. (d) Zelenin, K. N.; Kuznetsova, O. B.; Alekseyev, V. V.; Terentyev, P. B.; Torochesnikov, V. N.; Ovcharenko, V. V. Tetrahedron 1993, 49, 1257. (e) Zelenin, K. N.; Alekseyev, V. V.; Kuznetsova, O. B.; Torochesnikov, V. N.; Khorseeva, L. A. Tetrahedron 1993, 49, 5327.

3. Gruttadauria, M.; Lo Meo, P.; Noto, R. Tetrahedron 2001, 57, 1819.

4. Gruttadauria, M.; Aprile, C.; D’Anna, F; Lo Meo, P; Riela, S.; Noto, R. Tetrahedron 2001, 57,6815 . 
5. Gruttadauria, M.; Lo Meo, P.; Noto, R. Targets in Heterocyclic Systems 2001, 5, 31, and references therein.

6. Harmange, J. C.; Figadere, B. Tetrahedron: Asymmetry 1993, 4, 1711.

7. Bovin, T. L. B. Tetrahedron 1987, 43, 3309.

8. Bartlett, P. A. Tetrahedron 1980, 36, 2.

9. Semple, J. E.; Jouillie, M. Heterocycles 1980, 14, 1825.

10. Aprile, C.; Gruttadauria, M.; Amato, M. E.; D’Anna, F.; Lo Meo, P.; Riela, S.; Noto, R. Tetrahedron 2003, 59, 2241.

11. Silva, A. M. S.; Diana C. G. A.; Pinto, D. C. G. A.; Cavaleiro, J. A. S.; Levai, A.; Patonay T. ARKIVOC 2004, (vii), 106.

12. Cecil, A. R. L.; Brown, R. C. D. ARKIVOC 2001, (xi), 49.

13. Nair, V.; Balagopal, L.; Menon, R. S.; Ros, S.; Srinivas, R. ARKIVOC 2003, (viii), 199.

14. Tsoungas, P. G.; Diplas, A. I. Heteroatom Chem. 2003, 14, 642 and references therein.

15. Gibson, M. S. Tetrahedron 1962, 18, 1377.

16. Werber, G.; Buccheri, F.; Marino, M. L.; Ann. Chim. (I) 1972, 62, 11.

17. Gómez-Saiz, P.; Javier García-Tojal, J.; Maestro, M. A.; Mahía, J.; Arnaiz, F. J.; Lezama, L.; Teófilo Rojo T. Eur. J. Inorg. Chem. 2003, 2639 and references therein.

18. Gladstone, W. A. F.; Aylward, J. B.; Norman, R. O. C. J. Chem. Soc. (C) 1969, 2587.

19. Noto, R.; Buccheri, F.; Cusmano, G.; Gruttadauria, M.; Werber, G. J. Heterocyclic Chem. 1991, 28, 1421.

20. Gruttadauria, M.; Buccheri, F. ; Cusmano, G.; Lo Meo, P.; Noto, R.; Werber, G. J. Heterocycl. Chem. 1993, 30, 765.

21. Noto, R.; Lo Meo, P.; Gruttadauria, M.; Werber, G. J. Heterocycl. Chem. 1996, 33, 863.

22. Gruttadauria, M.; Lo Meo, P.; Noto, R.; Werber, G. Gazz. Chim. It. 1997, 127, 277.

23. Noto, R.; Lo Meo, P.; Gruttadauria, M.; Werber, G. J. Heterocycl. Chem. 1999, 36, 667.

24. Young, G.; Witham, E. J. Chem. Soc. 1900, 77, 224.

25. Ramachander, G.; Srinivasan, V. R. J. of Scientific and Ind. Res. Section B: Physical Sciences 1962, 21C, 44. To the best of our knowledge no example of reaction between thiosemicarbazones and TPBA has ever been reported.

26. Brousse, B. N.; Moglioni, A. G.; Martins Alho, M.; Álvarez-Larena, A.; Moltrasio G. Y.; D'Accorso N. B. ARKIVOC 2002, (x), 14.

27. Martins Alho, M. A.; Moglioni, A. G.; Brousse, B.; Moltrasio G. Y.; D'Accorso N. B. ARKIVOC 2000, (iv), 627.

28. Gassmann, P. G.; Campbell, G. A.; Frederick, R. C. J. Am. Chem. Soc. 1972, 94, 3884.

29. Gassmann, P. G.; Campbell, G. A. J. Am. Chem. Soc. 1972, 94, 3891.

30. O’Mahony, T. A. F.; Butler, R. N.; Scott, F., L. J. Chem. Soc., Perkin Trans. 2 1972, 1319.

31. Padhye, S. B.; Kauffmann, G. B. Coord. Chem. Rev. 1985, 63, 127.

32. Barone, V.; Cossi, M. J. Phys. Chem. A 1998, 102, 1995. 
33. It should be taken into account, indeed, that specifical solvation interactions such as hydrogen bond are not accounted for by COSMO method. Therefore, slightly underestimated solvation energies have to be expected everytime such interactions are presumably involved.

34. Although in ordinary metal-thiosemicarbazone complexes the organic molecule acts as a bidentate ligand, such a structural arrangment is unlikely to be an immediate precursor of any cyclo-oxidation product, because the iminic $\mathrm{C}$ and the $\mathrm{N}(4)$ atoms are rigidly held afar from each other. Therefore, in order to achieve the formation of the final triazole product, the disruption of the N(1)-metal bond and the formation of a "reactive" complex - in which the metal atom interacts only with the thioamide moiety - are needed. See ref. 20.

35. Young, G.; Eyre, W. J. Chem. Soc. 1901, 79, 54.

36. Frisch, M. J.; Trucks, G. W.; Schlegel, H. B.; Scuseria, G. E.; Robb, M. A.; Cheeseman, J. R.; Zakrzewski, V. G.; Montgomery, J. A. Jr.; Stratmann, R. E.; Burant, J. C.; Dapprich, S.; Millam, J. M.; Daniels, A. D.; Kudin, K. N.; Strain, M. C.; Farkas, O.; Tomasi, J.; Barone, V.; Cossi, M.; Cammi, R.; Mennucci, B.; Pomelli, C.; Adamo, C.; Clifford, S.; Ochterski, J.; Petersson, G. A.; Ayala, P. Y.; Cui, Q.; Morokuma, K.; Malick, D. K.; Rabuck, A. D.; Raghavachari, K.; Foresman, J. B.; Cioslowski, J.; Ortiz, J. V.; Stefanov, B. B.; Liu, G.; Liashenko, A.; Piskorz, P.; Komaromi, I.; Gomperts, R.; Martin, R. L.; Fox, D. J.; Keith, T.; Al-Laham, M. A.; Peng, C. Y.; Nanayakkara, A.; Gonzalez, C.; Challacombe, M.; Gill, P. M. W.; Johnson, B.; Chen, W.; Wong, M. W.; Andres, J. L.; Gonzalez, C.; Head-Gordon, M.; Replogle, E. S.; Pople, J. A. Gaussian 98, Revision A.6; Gaussian, Inc., Pittsburgh PA, 1998. 